\title{
THE EFFICACY OF FLECAINIDE VERSUS DIGOXIN IN THE MANAGEMENT OF FETAL SUPRAVENTRICULAR TACHYCARDIA
}

\author{
I. M. FROHN-MULDER*, P. A. STEWART ${ }^{\dagger}$, M. WITSENBURG*, N. S. DEN HOLLANDER ${ }^{\dagger}$, J. W. WLADIMIROFF ${ }^{\dagger}$, \\ J. HESS* \\ *Department of Pediatrics, subdivision of pediatric cardiology, Sophia Children's Hospital, University Hospital \\ Rotterdam, The Netherlands. \\ tDepartment of Obstetrics and Gynaecology, subdivision of prenatal diagnosis, University Hospital Rotterdam, \\ The Netherlands
}

\section{SUMMARY}

Fetal supraventricular tachycardia (SVT) can be successfully treated transplacentally, but in cases where fetal hydrops develops there is considerable morbidity and mortality. The present study was carried out to establish whether the introduction of flecainide altered obstetric management and fetal outcome. A retrospective analysis took place of 51 singleton pregnancies which were referred to the division of prenatal diagnosis because of fetal tachycardia between 1982 and 1993. SVT was documented in 50 out of 51 fetuses, one of which displayed a combination of extensive rhabdomyomas and severe hydrops and died shortly after referral. In the other fetus ventricular tachycardia was diagnosed. Of the remaining 49 fetuses, 14 did not receive any prenatal treatment, but nine needed postnatal treatment. Transplacental treatment of SVT took place in 35 fetuses, of which 22 presented without hydrops and 13 with hydrops. These subsets differed significantly with respect to restoration of normal sinus rhythm (73\% vs. $30 \% ; \mathrm{p}<0.001)$ and mortality (0\% vs. $46 \% ; \mathrm{p}<0.001$ ). Digoxin was effective in restoring sinus rhythm in 55 per cent of the non-hydropic fetuses but in only eight per cent of the hydropic fetuses. Flecainide was effective in restoring sinus rhythm in all non-hydropic fetuses where digoxin treatment failed, and in 43 per cent of hydropic fetuses. Administration of flecainide resulted in a significantly reduced mortality (p<0.001) compared with digoxin treatment. No adverse effects were seen. Postnatal anti-arrhythmic treatment was necessary in 23 infants. Treatment could be withdrawn within one year in all cases but one.

KEY wORDS: Fetal supraventricular tachycardia; anti-arrhythmic treatment; fetal hydrops; digoxin; flecainide

\section{INTRODUCTION}

Fetal tachycardia is a rare but challenging disorder and is usually of supraventricular origin. In most cases there is no underlying structural abnormality, although atrial septal aneurysm has

Addressee for correspondence: Prof. J.W. Wladimiroff, Dept. of Obstetrics and Gynaecology, Academic Hospital Rotterdam-Dijkzigt, Dr. Molewaterplein 40, 3015 GD Rotterdam, The Netherlands. Tel. +31 10463 3632; Fax: +31 104635826 . been associated with supraventricular tachycardia (SVT) (Stewart and Wladimiroff, 1988). Frequently, there is an association with Wolff Parkinson White (WPW) syndrome, but it may also arise from fetal myocarditis as a result of a viral infection (Ko et al., 1992). If untreated, SVT may lead to fetal hydrops and fetal or early neonatal death. An accurate diagnosis of the nature of the rhythm disturbance can be made by $\mathbf{M}$-mode echocardiography (Allan et al., 1983). Digoxin has been the drug of choice for treating SVT (Kleinman et al., 1985). It is administered to the mother and 
reaches the fetus transplacentally. In the presence of fetal hydrops placental transfer is diminished, often resulting in treatment failure. When digoxin fails to restore normal sinus rhythm (SR) several other drugs have been used, such as propranolol, kinidine, procainamide, verapamil and amiodarone, either given to the mother or directly to the fetus (Arnoux et al., 1987; Maxwell et al., 1988; Hansmann et al., 1991; Hallak et al., 1991; Jouppila et al., 1993). After the introduction of flecainide in 1988 adverse effects have been noted, especially in adults after myocardial infarction (Editorial, $N$. Engl. J. Med., 1989; Fish et al., 1991). We have retrospectively analysed the clinical presentation, treatment and outcome of a consecutive series of 49 patients with fetal SVT, with emphasis on the question as to whether the introduction of flecainide altered policy and outcome.

\section{MATERIAL AND METHODS}

We retrospectively studied the clinical data of 51 single pregnancies that were referred to the Division of Prenatal Diagnosis because of fetal tachycardia during the period 1982-1993. Gestational age ranged between 16 and 41 weeks (mean: $30 \pm 5.8$ ( \pm SD) wks). Pregnancy was otherwise uncomplicated in 49 cases, insulin dependent juvenile diabetes or pregnancy diabetes was present in the remaing two cases. Blood samples were taken from all women to assess possible viral infections. Cardiological examination of each pregnant woman was carried-out before transplacental treatment of the fetal tachycardia was initiated.

Fetal tachycardia was diagnosed by simultaneous $\mathrm{M}$-mode recording of atrial and ventricular cardiac activity using a Diasonics CV 100 (carrier frequency $3.5 \mathrm{MHz}$ ) or a Toshiba SSA 270 (carrier frequency $3.5 \mathrm{MHz}$ ). All fetuses were screened for structural abnormalities and for the presence of hydrops, which was considered to be present whenever there was pericardial or pleural effusion or when ascites was noted.

Management of fetal tachycardia was documented. To restore fetal sinus rhythm, digoxin was the first drug of choice. After maternal administration of a loading dose of $1 \mathrm{mg}$, a maintenance dose of $0.25 \mathrm{mg}$, three times a day, was given. Serum drug concentrations were measured and the dosage adjusted to maintain concentrations around 2 nanograms/milliliter $(\mathrm{ng} / \mathrm{ml})$. When sinus rhythm could not be achieved other drugs were administered to the pregnant woman such as verapamil; or occasionally propranolol, procainamide or amiodarone. As from January 1991, flecainide was selected as the first drug of choice in cases of fetal hydrops, and was also administered if treatment with digoxin failed to restore sinus rhythm in the non-hydropic fetus. Flecainide was administered orally 3 times $100 \mathrm{mg}$ a day; the dosage was adjusted if necessary to keep serum drug concentrations between $0 \cdot 5-1 \mathrm{microgram} / \mathrm{milliliter}$ $(\mathrm{mcg} / \mathrm{ml})$.

Gestational age at referral as well as time, mode and place of delivery and fetal outcome were documented. Neonatal heart rate was recorded by ECG, which was analysed for pre-excitation. Medication and duration of therapy were noted.

Statistical analysis was performed using Fisher's exact test. Statistical significance was set at $\mathrm{p}<0.05$.

\section{RESULTS}

Fifty fetuses demonstrated SVT, 14 of which presented as atrial flutter $(28 \%)$. Hydrops was present in 17 fetuses (34\%). Anti-arrhythmic treatment was not initiated in one fetus because of extensive rhabdomyomas and severe hydrops; fetal death occurred two days later. Another fetus displayed ventricular tachycardia (Polak et al., 1989). Both these fetuses were eliminated from the follow-up. An atrial septal aneurysm was established in three fetuses. No other structural abnormalities were found and no viral infections were documented.

Of the remaining 49 fetuses, 35 were managed by transplacental medication. Reasons for not treating the other 14 fetuses are summarized in Table I. There was no mortality in this group. Nine of these infants needed anti-arrhythmic therapy after birth. Six infants received digoxin in treatment alone, three infants needed a combination of digoxin and propranolol. A small muscular ventricular septal defect proved to be present in one infant, which later closed spontaneously. Followup showed normal development of all these infants.

Data on the 35 treated fetuses are shown in Figures 1 and 2. Two groups could be distinguished according to the presence or absence of fetal hydrops. In 22 fetuses there was no hydrops (Figure 1). Digoxin was the first drug of choice, 
Table I-Data on 14 fetuses with supraventicular tachycardia (SVT) which did not receive transplacental antiarrhythmic treatment

\begin{tabular}{lcc}
\hline & & $\begin{array}{c}\text { Fetuses not treated } \\
(\mathrm{n}=14)\end{array}$ \\
\hline - intermittent SVT & $(\geq 37 \mathrm{wks})$ & 7 \\
- in labour & $(37.5 \mathrm{wks})$ & 2 \\
- induction of labour & $(32-36 \mathrm{wks})$ & 1 \\
- severe hydrops in advanced pregnancy & & 4 \\
Caesarean section & & 0 \\
\hline Mortality: & & 0 \\
\hline
\end{tabular}

which resulted in sinus rhythm in 12 fetuses. Flecainide was given to four fetuses in whom digoxin therapy was not effective, restoring sinus rhythm in all. In five out of the remaining six cases, pregnancy was terminated by means of Caesarean section with the aim of controlling SVT postnatally. In the other fetus, SVT was intermittent and expectant obstetric management was adopted. There were no signs of pre-excitation postnatally. There was no mortality in this group. Postnatal treatment was necessary in 19 infants. In 17 infants digoxin alone was sufficient to control normal rhythm. In two infants with SVT flecainide was given after digoxin failure. These two infants had also not reacted to digoxin prenatally. Postnatal treatment was discontinued after one week in one case because of bradycardia. In all other cases, therapy was discontinued after one year, without recurrence of SVT.

Hydrops was present in 13 fetuses (Figure 2). Initiation of digoxin therapy resulted in sinus rhythm in one fetus. Before the introduction of flecainide in 1991, a range of other anti-arryhthmic drugs was used in five fetuses, which were ineffective in establishing sinus rhythm. All five fetuses died. Of the seven fetuses that were managed by flecainide, three developed sinus rhythm. In the other four fetuses it was decided to perform a Caesarean section, because of ongoing tachycardia and progressive hydrops. In these instances, gestational age (28-35 wks) was considered to be sufficiently advanced to promote delivery and thus create the possibility of treating the infants directly. Of the seven newborn which presented with hydrops, all but one needed treatment. Two infants remained in sinus rate by digoxin alone, in one case propranolol was added. In two infants, flecainide was continued. In these infants therapy could be withdrawn after one year without recurrence of SVT. In another infant, which appeared to have an ectopic atrial tachycardia and was difficult to manage prenatally, control of heart rate was finally achieved by sotacor. When this medication was withdrawn after two years there was a reccurrence of SVT within six months, necessitating further sotacor medication. One infant died on the second day after delivery because of complications of ongoing tachycardia and severe hydrops at 31 weeks of gestation. Overall mortality in the hydropic group was 46 per cent.

The two groups differed significantly with respect to restoration of normal sinus rhythm: $73 \%$ in the non-hydropic group versus 30 per cent in the hydropic group ( $\mathrm{p}<0.001)$, and mortality: $0 \%$ in the non-hydropic group versus 46 per cent in the hydropic group ( $<<0.001)$.

When comparing the efficacy of digoxin and flecainide, it can be seen that digoxin was effective in restoring sinus rhythm in 55 per cent of the nonhydropic fetuses. In cases of digoxin failure, flecainide proved to be effective in all nonhydropic fetuses $(\mathrm{p}<0.05)$. Flecainide was also effective in restoring sinus rhythm in 43 per cent of the hydropic fetuses, while digoxin converted SVT to sinus rhythm in only one of the hydropic fetuses ( 8 per cent). This difference was, however, not significant. Mortality was significantly reduced in the hydropic fetuses after the introduction of flecainide $(p<0.001)$. No adverse effects were seen with either digoxin or flecainide. 


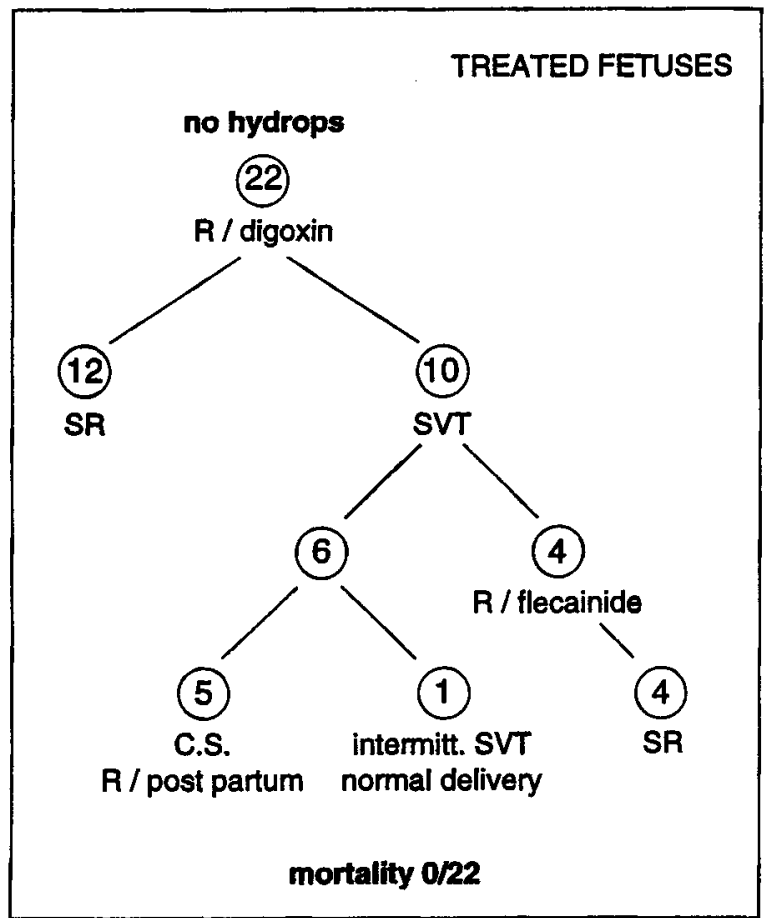

Fig. 1-Data on 22 non-hydropic fetuses with supraventricular tachycardia (SVT) receving transplacental anti-anhythmic treatment $S R=$ sinus rhythm; $C S=$ Caesarean section; $R=$ treatment

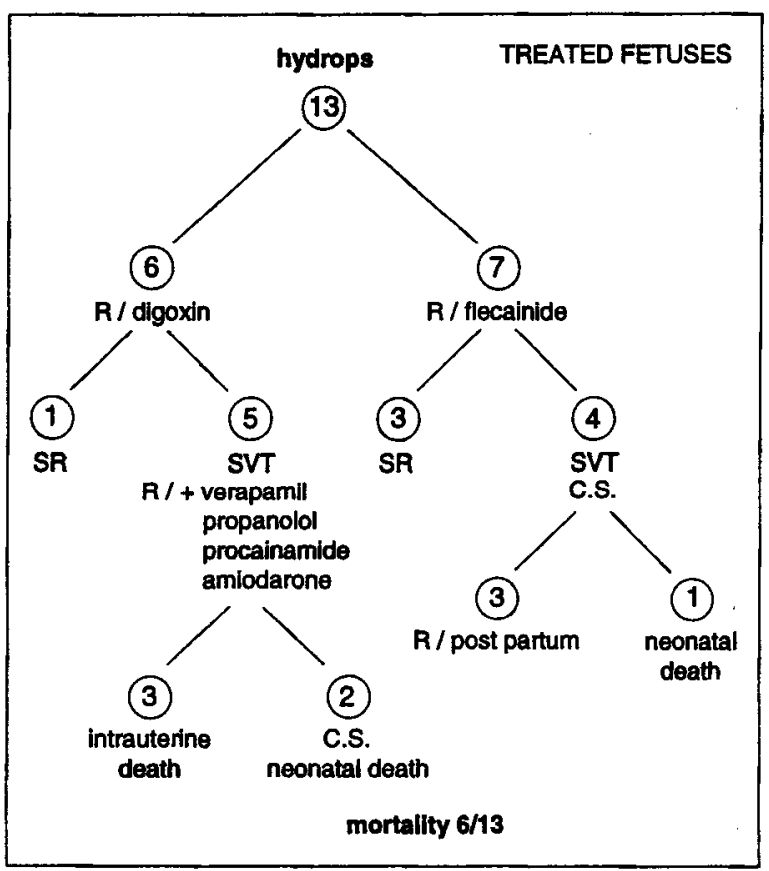

Fig. 2-Data on 13 hydropic fetuses with supraventricular tachycardia (SVT) receiving transplacental anti-arrhythmic treatment $S R=$ sinus rhythm; $C S=$ Caesarean section; $R=$ treatment

\section{DISCUSSION}

A retrospective analysis of treatment modalities for fetal SVT is presented. Emphasis was put on the anti-arrhythmic agents digoxin and flecainide. It is demonstrated that fetal hydrops is a strong prognostic determinant of fetal SVT. The present study shows that mortality was 35 per cent in the presence of hydrops as opposed to nil in the nonhydropic fetus. This is in agreement with other reports (Bergmans et al., 1985; Maxwell et al., 1988; Hansmann et al., 1991; van Engelen et al., 1994). In addition, conversion into sinus rhythm was considerably less successful in the presence of fetal hydrops.

The success rate of digoxin turned out to be lower in hydropic fetuses than in non-hydropic fetuses (Younis and Granat, 1987; Hallak et al., 1991). We experienced a clear association between pre- and postnatal success rates of both drugs in individual cases, especially with regard to ectopic atrial tachycardia being difficult to treat (Kleinman et al., 1985; Azancot-Benisty et al., 1992).

Digoxin has been the drug of choice in the treatment of fetal SVT (Kleinman et al., 1985; Allan et al., 1991). Flecainide is a potent class Ic antiarrhythmic drug, which has been used in infants with SVT since 1988 (Wren and Hunter, 1988). In 1991, favourable results were published in a first series of 14 cases of fetal tachycardia treated with flecainide (Allan et al., 1991). At the same time serious side effects were reported from the use of flecainide in patients who had suffered a myocardial infarction (Editorial, N. Engl. J. Med., 1989) and restricted use of flecainide was recommended (Perry et al., 1989; Epstein, 1989; Fish et al., 1991). In our centre flecainide was introduced in the treatment of fetal SVT in 1991. Flecainide proved to be more successful in converting fetal SVT into sinus rhythm in cases in which digoxin treatment had failed and in cases presenting with fetal hydrops. Similar observations were made elsewhere (Perry et al., 1991; Kofinas et al., 1991; Mills, 1992). We did not experience any adverse effects. A similar experience was reported elsewhere in a series of fetuses and infants with SVT (Perry and Garson, 1992; van Engelen et al., 1994).

In fetal hydrops due to arrhythmia a variety of other drugs have been suggested. Verapamil is a calcium antagonist, which is known for its serious side effects in the neonate and infant, of which 
asystole is the most important (Garson, 1987). In the five cases in which we used verapamil, it was concluded that fetal death was clearly related to this drug in one fetus which died in utero two hours after an intravenous dose of $10 \mathrm{mg}$ of verapamil to the mother. Another fetus died suddenly in utero eight days after conversion to sinus rhythm following 14 days of treatment with digoxin and verapamil. A case of fetal death following successful conversion of fetal SVT with digoxin and verapamil has been reported elsewhere (Owen et al., 1988). Therefore, in our opinion the use of verapamil in fetal SVT should be avoided, as has also been suggested by others (Garson, 1987; Kleinman and Copel, 1991). Amiodarone is a class III antiarrhythmic drug with a long elimination time. It has been used in matemal therapy, but also in direct fetal therapy, avoiding transplacental transfer (Jouppila et al., 1993). This drug is known for its adverse effects, especially on the developing thyroid gland (de Wolf et al., 1988). In our series amiodarone was used only once, and did not achieve conversion to sinus rhythm.

Fetal tachycardia is usually of supraventricular origin, and only very rarely is a ventricular tachycardia diagnosed. Structural abnormalities are seldom found in fetal SVT, although cardiac tumours and atrial septal aneurysm have been associated with SVT. SVT may also be related to fetal myocarditis or pre-excitation syndrome. In our series structural abnormalities were found in only five out of 51 fetuses. One fetus, with extensive rhabdomyomas died in utero. In another infant a small muscular ventricular septal defect was diagnosed after birth, which was probably unrelated to the tachycardia. An atrial septal aneurysm was established in three fetuses. The low incidence of atrial aneurysm in our series does not support the findings of others that these aneurysms could play an etiological role in the development of SVT. No viral infections were documented in our study group. Postnatal ECG showed pre-excitation syndrome in four infants $(8$ per cent). It has recently been demonstrated in pediatric patients that an accessory connection is the most frequent mechanism of SVT (73 per cent) (Ko et al., 1992). Since normal AV-conduction may occur in the presence of a pre-excitation syndrome, a normal postnatal ECG does not rule out the presence of this syndrome. It is likely that additional infants will prove to have this feature later in life.
It can be concluded that, in our series, flecainide was shown to be more successful than digoxin in restoring sinus rhythm during fetal SVT. In the absence of fetal hydrops digoxin is a potent drug for the conversion of tachycardia into sinus rhythm. Where digoxin fails to restore sinus rhythm, flecainide may be successful. In hydropic fetuses there is a high risk of perinatal mortality, since transplacental drug transfer is hampered and digoxin, therefore, appears to be of limited value. Verapamil has serious side effects and should be avoided as a mode of treatment. Furthermore, in our experience, administration of flecainide is associated with a significant reduction in perinatal mortality, with no adverse side effects being observed.

\section{REFERENCES}

Allan, L.D., Anderson, R.H., Sullivan, I.D., Campbell, S., Holt, D.W., Tynan, M. (1983). Evaluation of fetal arrhythmias by echocardiography, Br. Heart J., 50, 240-245.

Allan, L.D., Chita, S.K., Sharland, G.K., Maxwell, D., Priestley, K. (1991). Flecainide in the treatment of fetal tachycardias, Br. Heart J., 65, 46-48.

Arnoux, P., Seyral, P., Llurens, M., Djiane, P., Potier, A., Unal, D., Cano, J.P., Serradimigni, A., Rouault, F. (1987). Amiodarone and digoxin for refractory fetal tachycardia, Am. J. Cardiol., 59, 166-167.

Azancot-Benisty, A., Jacqz-Aigrain, E., Guirgis, N.M., Decrepy, A.,- Oury, J.F., Blot, P. (1992). Clinical and pharmacologic study of fetal supraventricular tachyarrythmias, J. Pediatr., 121, 608-613.

Bergmans, M.G.M., Jarker, G.H., Kock, H.C.L.V. (1985). Fetal supraventricular tachycardia: Review of the literature, Obstet. Gynecol. Surv., 40, 61-68.

Editorial (1989). Preliminary report: effect of encainide and flecainide on mortality in a randomized trial of arrhythmia suppression after myocardial infarction, N. Engl. J. Med., 321, 406-412.

van Engelen, A.D., Weijtens, O., Brenner, J.I., Kleinman, C.S., Copel, J.A., Stoutenbeek, P., Meijboom, E.J. (1994). Management outcome and follow-up of fetal tachycardia, J. Am. Coll. Cardiol., 24, 1371-1375.

Epstein, A.E. (1989). Flecainide for Pediatric arrhythmias: Do children behave like little adults? $J$. Am. Coll. Cardiol., 14, 192-193.

Fish, F.A., Gillette, P.C., Benson, D.W. (1991). Proarrhythmia, cardiac arrest and death in young patients receiving encainide and flecainide, J. Am. Coll. Cardiol., 18, 356-365.

Garson, A. (1987). Medicolegal problems in the 
management of cardiac arrhythmias in children, Pediatrics, 79, 84-88.

Hallak, M., Neerhof, M.G., Perry, R., Nazir, M., Huhta, J.C. (1991). Fetal supraventricular tachycardia and hydrops fetalis: Combined intensive, direct, and transplacental therapy. Obstet. Gynecol., 78, 523527.

Hansmann, M., Gembruch, U., Bald, R., Manz, M., Redel, D.A. (1991). Fetal tachyarrhythmias: transplacental and direct treatment of the fetus-a report of 60 cases, Ultrasound Obstet. Gynecol., 1, 162-170.

Jouppila, P., Mäkkărałinen, L., Räsänen, J., Valkama, M., Paavilainen, T. (1993). Aggresive direct treatment of a fetus with supraventricular tachycardia and hydrops fetalis, Ultrasound Obstet. Gynecol., 3, 279-283.

Kleinman, C.S., Copel, J.A., Weinstein, E.M., Santulli, T.V., Hobbins, J.C. (1985). In utero diagnosis and treatment of fetal supraventricular tachycardia, Sem. Perinatol., 9 (2), 113-119.

Kleinman, C.S., Copel, J.A. (1991). Electrophysiological principles and fetal anti-arrythmic therapy, Ultrasound Obstet. Gynecol., 1, 286-297.

Ko, J.K., Deal, B.J., Strasburger J.F., Benson, D.W. (1992). Supraventricular tachycardia mechanisms and their age distribution in pediatric patients, Am. J. Cardiol., 69, 1028-1032.

Kofinas, A.D., Simon, N.V., Sagel, H., Lyttle, E., Smith, N., King, K. (1991) Treatment of fetal supraventricular with flecainide acetate after digoxin failure, Am. J. Gynecol., 165, 630-631.

Maxwell, D.J., Crawford, D.C., Curry, P.V.M., Tynan, M.J., Allan, L.D. (1988). Obstetric importance, diagnosis, and management of fetal tachycardias, Brit. Med. J., 297, 107-110.
Mills, M. (1992). Treatment of fetal supraventricular tachycardia with flecainide acetate after digoxin failure, Am. J. Obstet. Gynecol., 166, 1863-1870.

Owen, J., Colvin, E.V., Davis, R.O. (1988). Fetal death after succesful conversion of fetal supraventricular tachycardia with digoxin and verapamil, Am. J. Obstet. Gynecol., 158, 1169-1170.

Perry, J.C., McQuinn, R.L., Smith jr, R.T., Gothing, C., Fredell, P., Garson jr, A. (1989). Flecainide acetate for resistant anthytmias in the young: Efficacy and pharmacokinetics, J. Am. Coll. Cardiol., 14, 185-191.

Perry, J.C., Ayres, N.A., Carpenter, R.J. (1991). Fetal supraventricular tachycardia treated with flecainide acetate, J. Pediatr, 118, 303-305.

Perry, J.C., Garson, A. (1992). Flecainide acetate for treatment of tachyarrhythmias in children: Review of world literature on efficacy, safety, and dosing, Am. Heart J., 124 (6), 1614-1621.

Polak, P.E., Stewart, P.A., Hess, J. (1989). Complete atrioventricular dissociation and His bundle tachycardia in a newborn: problems in prenatal diagnosis and postnatal management, Int. $J$. Cardiol., 22, 269-271.

Stewart, P.A., Wladimiroff, J.W. (1988). Fetal atrial arrhythmias associated with redundancy/ aneurysm of the foramen ovale, J. Clin Ultrasound, 16, 643-650.

Wolf de, D., Schepper de, J., Verhaaren, H., Smitz, J., Sacre-Smits, L. (1988). Congenital hypothyroid goiter and amiodarone, Acta Poediatr. Scand, 77, 616-618.

Wren, C., Hunter, S. (1988). Maternal administration of flecainide to terminate and suppress fetal tachycardia, Br. Med. J., 296, 249-253.

Younis, J.S., Granat, M. (1987). Insufficient transplacental digoxin transfer in severe hydrops fetalis, Am. J. Obstet. Gynecol., 157, 1268-1269. 